\title{
An ecological economic assessment of risk-reducing effects of species diversity in managed grasslands
}

Journal Article

Author(s):

Finger, Robert (1); Buchmann, Nina (1)

Publication date:

2015-02

Permanent link:

https://doi.org/10.3929/ethz-b-000097853

Rights / license:

Creative Commons Attribution-NonCommercial-NoDerivatives 4.0 International

Originally published in:

Ecological Economics 110, https://doi.org/10.1016/j.ecolecon.2014.12.019 


\section{Postprint}

This is the accepted version of a paper published in Ecological Economics. This paper has been peerreviewed but does not include the final publisher proof-corrections or journal pagination.

\section{Citation for the original published paper:}

Finger, R., Buchmann, N. (2015). An ecological economic assessment of risk-reducing effects of species diversity in managed grasslands. Ecological Economics 110: 89-97. https://doi.org/10.1016/j.ecolecon.2014.12.019

Access to the published version may require subscription.

N.B. When citing this work, cite the original published paper. 


\title{
An ecological economic assessment of risk-reducing effects of species diversity in managed grasslands
}

\author{
Authors: Robert Finger, Nina Buchmann
}

\begin{abstract}
Over the last decade, it has been shown in the ecology literature that species diversity increases yield stability in managed grasslands. Here, we develop and apply ecological economic and econometric frameworks to evaluate potential risk-reducing effects of species diversity in terms of yields and their temporal stability from a farmer's perspective. Our empirical analysis is based on a rich panel data set obtained from a diversity experiment covering in total 60 species and a period of 6 years. We find empirical evidence for the risk-reducing effect of species diversity and the economic assessment reveals significant insurance values associated with diversity for a risk-averse decision maker. Thus, the economic value of diversity would be underestimated if not accounting for this property, and species diversity may serve as valuable ex-ante risk management strategy.
\end{abstract}

Keywords: species diversity, risk, insurance value, grassland, yield, stability

\section{Introduction}

There is ample evidence for a positive effect of species diversity on net primary productivity of ecosystems (see e.g. Cardinale et al. 2012, Hector et al., 1999, Hooper et al., 2012, Isbell et al., 2011, Tilman et al., 2005). Furthermore, a wide body of research has indicated an increase in the resilience and resistance of ecosystems with higher species diversity (e.g. Roscher et al., 2008, Baumgärtner, 2007, Haddad et al., 2011, Lehmann and Tilman, 2000, Walker et al., 1999, Naeem and Li, 1997). A particular focus of this literature was laid on grassland systems, due to their high relevance for feed and food production and for the provision of ecosystem services. From a farmer's perspective, increased on-field diversity may thus imply higher mean profitability (e.g. Hodgson et al., 2005). Moreover, diverse grassland systems have been found to be more stable in terms of production (Hector et al., 2010, Proulx et al., 2010, Marquard et al., 2009). For instance, higher diversity has been found to reduce the vulnerability of grassland to climatic extreme events such as droughts as well as to pests and diseases (e.g. Kahmen et al., 2005, Lin 2011, Sanderson et al., 2004, Vogel et al., 2012). The higher temporal stability of production resulting from higher species diversity might be additionally valued by farmers because a less volatile biomass production increases the utility of a risk-averse decision maker. Along these lines, Lugnot and Martin (2013) show that French farmers and farm advisors perceive the risk reduction property of plant diversity as important factor, and diversity is perceived to serve as an insurance-like mechanism. Thus, the economic value of on-field species diversity for farmers might be substantially underestimated if only mean returns from grassland yields are considered. If farmers 
account for these effects in their grassland management decisions, this also underlines that farmers' risk preferences might shape agroecosystem diversity (e.g. Di Falco, 2012, Mouysset et al., 2013).

The potentially risk decreasing property of species diversity and its relevance for optimal management of ecosystems has been the subject of several recent studies (e.g. Baumgärtner, 2007, Baumgärtner and Quaas, 2009, 2010, Derissen et al., 2011, Di Falco and Chavas, 2006, 2009, Dörschner and Musshoff, 2013, Koellner and Schmitz, 2006, Schläpfer et al., 2002). However, the empirical literature investigating the relationship between species diversity in grasslands, production risks and its valuation from the farmers' perspective is still scarce (see e.g. Baumgärtner and Quaas, 2010, Di Falco, 2012, Dörschner and Musshoff, 2013, Koellner and Schmitz 2006, for recent overviews). Furthermore, these empirical studies have relied either on a small number of years (e.g. Schläpfer et al., 2002), on combinations of different, independent sets of short-term experimental data (e.g. Koellner and Schmitz 2006) or highly aggregated data (e.g. Dörschner and Musshoff, 2013). Thus, these approaches have not fully accounted for the field-level effects of species diversity on (the distribution of) grassland yields over time (e.g. arising from variable weather conditions) and space (e.g. due to different biophysical conditions). Furthermore, earlier research has often relied on comparisons of a limited number of grassland systems with respect to its species diversity (e.g. Dörschner and Musshoff, 2013, Schläpfer et al., 2002). Overall, these studies do not allow to sufficiently specify and test the relationship between species diversity and production risks.

Thus, based on a comprehensive panel dataset from the Jena Experiment, one of the longest running biodiversity experiments in Europe (see e.g. Roscher et al., 2004, and Weigelt et al., 2010 for details). we investigate the value of species diversity in managed grassland from the farmer's perspective with a specific focus on its effects on production risks. We develop an ecological economic and econometric framework capturing the relationship between species diversity and production risk. Our empirical analysis estimates stochastic specifications of production functions, which are then combined with the developed economic model, integrating both components in the assessment of risk reducing effects of species diversity in managed grasslands. Finally, this setup is used to derive certainty equivalents, risk premiums as well as insurance values of diversity under various scenarios for output prices, risk aversion and species diversity.

The remainder of this article is structured as follows. First, we present an ecological background describing the mechanisms underlying the relationship between species diversity and grassland production in section 2. This background is used to develop an ecological economic and econometric framework that will be presented in section 3 . In sections 4 and 5, data and results are presented, while concluding remarks are content of section 6. 
The concept of increased ecosystem stability with increasing biodiversity is one of the core theories in plant ecology, particularly in biodiversity-ecosystem functioning studies (e.g., Hooper et al., 2005, Lehman and Tilman, 2000, McCann, 2000, Tilman et al., 2006, Yachi and Loreau, 1999). Most experimental studies have focused on plant community biomass, e.g., grassland yield, to test this theory in experimental grassland systems, just like in the Jena Experiment (Roscher et al., 2004). Often, yield stability over time has been one of the main interests, particularly in the long-term grassland biodiversity experiments (such as the Cedar Creek Experiment of Tilman and coworkers or the Jena Experiment). Temporal yield stability refers to the fact that grasslands withstand environmental impacts and keep up their biomass production, therefore providing forage yields with a low temporal variation. Recently, Proulx et al. (2010) could show that temporal stability for many ecosystem functions was higher in species-rich than in species-poor grasslands, indicated by temporal variations of these processes being lower in species-rich relative to species-poor grasslands, also known as the "insurance effect" (e.g. Ehrlich and Ehrlich, 1981, Yachi and Loreau, 1999). The "insurance effect" is based on the likelihood of more diverse responses to disturbances such as drought or pests expressed (response diversity) and of more diverse resource niches occupied (niche complementarity) in a diverse compared to a less diverse plant community or monoculture. This was true not only for biomass production, but for many other above- and belowground processes, across trophic levels and at different scales of organization (community to ecosystem levels). Linking this result from the ecology literature to a valuation of this insurance effect from an economic perspective is, however, scarce.

Niche complementarity, i.e., a mechanism where plant species growing together in species-rich communities specialize in taking up resources, is intensively studied as the basis for the positive biodiversity-ecosystem productivity relationships (e.g., Loreau et al., 2002). In terms of nutrient or water use, niche complementarity refers to the fact that plants take up resources in different places within the soil profile, during different times or in different forms, and thus jointly exploit the available resource more efficiently than in monoculture, resulting in higher ecosystem functions, for example biomass production. Over the last decade, the search to find the underlying mechanisms of complementarity has often focussed on nutrients (mainly nitrogen) (e.g., Balvanera et al., 2006, Di Falco, 2012, Fargione et al., 2007) as well as - although to a lesser extent - on light (Hautier et al., 2009, Spehn et al., 2000) and water use (Caldeira et al., 2001, De Boeck et al., 2006). Also in the Jena Experiment, nitrogen and light use (Bessler et al., 2012, Gubsch et al., 2011, Roscher et al., 2011a,b,c) have been reported to contribute to the overall complementarity effect (Marquard et al., 2009). The high $\mathrm{N}$ uptake in diverse mixtures thus not only led to higher aboveground productivity, but also to higher nitrogen pools with diversity (Oelmann et al. 2011). In addition, facilitation among species also plays an important role in biodiversity-ecosystem functioning relationships (e.g. Hooper et al., 2005). A key example of facilitation is the presence of legumes in a plant community: (1) due to their ability to fix atmospheric 
$\mathrm{N}_{2}$ via their root symbionts, legumes use less mineral nitrogen from the soil, which in turn is then available for non-legume plants (e.g. Temperton et al., 2007); and (2) due to their high tissue nitrogen concentration, neighboring plants benefit from the additional high nitrogen input into the soil when soil microbes mineralize dead legume tissues. In the Jena Experiment, clear indications for a facilitative role for legumes were found in the main experiment (Temperton et al., 2007). Data further suggested that the main driving force behind such facilitative interactions in plots containing legumes was reduced competition for soil nitrate. Consequently, the presence of legumes (as well as tall herbs) had a strong positive effect on annual yield production (Marquard et al., 2009). However, despite clear evidence of facilitation by legumes in many studies, the wide-spread relationship between species diversity and productivity is not dominantly driven by legumes, as convincingly shown by van Ruijven and Berendse (2003) in a biodiversity study without any legume species. A third mechanism, the selection effect, has also been discussed extensively in this context (Huston, 1997, Loreau et al., 2002). With increasing biodiversity, the chance to include a high-productive species also increases, resulting in high yields in diverse communities. For the Jena Experiment, it has been shown that the selection effect decreased over time (Marquard et al., 2009), indicating that differences among plant species in resource niches become more and more important (i.e., niche complementarity), while the importance of individual species diminished over time. All three mechanisms contribute to the positive biodiversity-productivity relationships. While their exact shapes can differ among different studies, these relationships typically first increase very steeply, before saturating at a certain extent of diversity.

\section{Conceptual and methodological framework}

In this section, we first develop an ecological economic framework for the valuation of species diversity in grasslands from the perspective of a risk-averse farmer. Based on this framework and the background of the ecological background summarized above, an econometric approach is derived to assess the empirical relationship between species diversity and the distribution of returns from grassland production. Finally, we present the parameterisation used in our analysis to investigate farmers' valuation of species diversity under different scenarios.

\subsection{An ecological economic perspective on species diversity}

In order to analyze the potential on-farm economic benefits arising from the risk reducing property of species diversity in grasslands, we consider the perspective of a farm household. Without loss of generality, we assume that the grassland yield $\tilde{y}$ is a random variable that is a function of (controllable) species diversity $\mathrm{D}$ and (non-controllable) environmental conditions reflected by the factor e. These factors determine the stochasticity of production levels, so that following Just and Pope $(1978,1979)$ the relationship between yield and species diversity in a changing environment can be described as $\tilde{y}=$ 
$f_{1}(D)+\mathrm{e}\left[f_{2}(D)\right]^{1 / 2}$, where $f_{1}(D)$ is the deterministic production function describing expected production levels in response to species diversity, and the term e $\left[f_{2}(D)\right]^{1 / 2}$ captures the stochasticity of grassland production. We assume $E(\mathrm{e})=0$ and $\operatorname{Var}(\mathrm{e})>0$, where $E(\cdot)$ is the expectation operator. Thus, the expected production level depends on the deterministic part of the production function, i.e. $E(\tilde{y})=f_{1}(D)$, and the yield variance is influenced by general production risks, e.g. influenced by environmental conditions, and the yield variance function $f_{2}: \operatorname{Var}(\tilde{y})=\operatorname{Var}(e) f_{2}(D)$. Of particular interest for our analysis is the assumption that $f_{2}$ is dependent of $\mathrm{D}$, i.e. we assume that the variance of grassland yields is affected by species diversity.

An expected yield level of $f_{1}(D)$ is produced at costs $C(D)$ and is sold at price $p$, generating a nondeterministic income of $\pi(D)=p \tilde{y}(D)-C(D)$. We use a von Neumann Morgenstern utility function $U($.$) to represent (risk) preferences of the farm household (Chavas, 2004). The risk stemming from$ fluctuating grassland yields causes implicit costs of risk bearing for the household that are approximated by the risk premium $R$. For a risk-averse decision maker, these risks are a burden, and the risk premium is positive ${ }^{1} \mathrm{R}>0$, reflecting a concave utility function with $U^{\prime}>0$ and $U^{\prime \prime}<0$. The risk premium can be interpreted as an amount of money a decision maker would be willing to pay to substitute the random profit $\pi$ by a non-random payoff, equal to the expected value of profits $E(\pi(D))$, so that

$$
E U(\pi(D))=U(E(\pi(D))-R(D))
$$

where $E(\pi(D))-R(D)=C E$, i.e. is the certainty equivalent (CE) of profits. Thus, CE represents a non-random payoff that in terms of utility is rated equivalent to the random profit $\pi$. Following Pratt (1964), the risk premium can be approximated as

$$
R=0.5 r \sigma_{\pi}^{2}(D)
$$

where $\sigma_{\pi}^{2}$ is the variance of profits that is a function of $D$, i.e. $\sigma_{\pi}^{2}=\sigma_{\pi}^{2}(D)$, and $\mathrm{r}$ denotes the ArrowPratt risk aversion coefficient that is defined as $r=-U^{\prime \prime} / U^{\prime}$. Focusing on production risks in grassland management, the output price $\mathrm{p}$ is assumed to be deterministic, so that the variance of profits is $\sigma_{\pi}^{2}=$ $p^{2} \sigma_{y}^{2}$. Recalling that the relationship between the variance of grassland yields and species diversity is captured by the yield variance function $f_{2}($.$) so that \sigma_{y}^{2}=\operatorname{Var}(e) f_{2}(D)$. The marginal effect of species diversity on the risk premium is thus defined as:

$$
\partial R / \partial D=0.5 r p^{2} \operatorname{Var}(e) \partial f_{2} / \partial D=-V(D)
$$

The negative value of this first derivative represents the insurance value of species diversity $V(D)$, quantifying the property to reduce the risk premium (Baumgärtner, 2007). Thus, this insurance value $V(D)$ reflects farmers' utility gains arising from the yield stabilizing effect of species diversity. The insurance value contains both a farmer-specific component (the coefficient of risk aversion $r$ ) and an objectively measurable component (the marginal yield variability reducing effect of species diversity $\partial f_{2} / \partial D$ ). If species diversity is decreasing the risk so that $\partial f_{2} / \partial D \leq 0$, an increase in $D$ decreases the risk premium $\partial R / \partial D \leq 0$, i.e. an increase in $\mathrm{D}$ decreases the implicit costs of risk for the farmer. This

\footnotetext{
${ }^{1} \mathrm{R}=0$ and $\mathrm{R}<0$ for risk neutral and risk loving decision makers.
} 
property is increasing with $r$, i.e. $\partial^{2} R / \partial D \delta r=0.5 p^{2} \operatorname{Var}(e) \partial f_{2} / \partial D \leq 0$, indicating that an increase in risk aversion increases the insurance value of species diversity. In agreement with the literature (e.g. Baumgärtner, 2007) (and our empirical analysis), there is a saturating effect of species diversity on yield stability, $\partial^{2} f_{2} / \partial D^{2}>0$, so that the insurance value of species diversity is decreasing with $\mathrm{D}$ : $\partial^{2} R / \partial D^{2}=0.5 r p^{2} \operatorname{Var}(e) \partial^{2} f_{2} / \partial D^{2} \geq 0$.

Combining information of species diversity effects on both expected profits and the risk premium the certainty equivalent maximizing condition for the optimal level of species diversity is as follows ${ }^{2}$ :

$$
M B=p \partial f_{1} / \partial D-0.5 r p^{2} \operatorname{Var}(e) \partial f_{2} / \partial D=\partial C / \partial D=M C
$$

The right hand side of equation 4 represents the marginal costs $(M C)$, which has to be equal to the marginal benefits $(M B)$ to satisfy certainty maximizing diversity levels. The latter term consists of a marginal gain in expected revenues due to increasing species diversity and its insurance value. It shows that the marginal benefit of species diversity is i) increasing with the price $\mathrm{p}$ for grass yield, $\partial M B / \partial p \geq$ 0 ; ii) increasing with the risk aversion of the farmer, $\partial M B / \partial r \geq 0$; and iii) decreasing with the level of species diversity $3 M B / \partial D \leq 0$. Increasing species diversity induces at least short-term costs for the farmer (Dörschner and Musshoff, 2013) that may comprise direct costs such as establishment costs for seeds, management, etc., but also opportunity costs associated with higher species diversity. The latter arise if higher species diversity is achieved by an increase of grassland acreage at the expense of alternative on-farm activities, or associated with giving up alternative, more profitable, production methods. Thus, marginal costs are positive and increasing with $\mathrm{D}: \partial C / \partial D \geq 0$ and $\partial^{2} C / \partial D^{2} \geq 0$ (Baumgärtner, 2007) ${ }^{4}$. In our analysis, however, we focus on the total and marginal benefits of species diversity in grassland systems, and particularly aim to quantify its insurance value ${ }^{5}$. Thus, we specify the relationship between species diversity and the mean as well as the variance of grassland yields using the econometric framework presented in the subsequent section.

\subsection{Econometric framework}

Next, we derive an econometric framework to empirically assess the relationship between species diversity and the distribution of grassland yields. We identify diversity effects on mean and variance of grassland yields, using a stochastic specification of a production function following Just and Pope (1978,

\footnotetext{
${ }^{2}$ Reflecting the property of our empirical application (i.e. an experimental setup with constant management and variation in species diversity only), we do not consider other inputs in our analysis. Thus, we analyse effects of species diversity conditional to the management setup used. But, other management decisions, such as fertilizer use, may interact directly (by affecting species composition) and indirectly (by affecting production risks) with optimal management in respect to species diversity, see e.g. Di Falco and Chavas (2006) for examples.

${ }^{3}$ Note that $\partial^{2} f_{1} / \partial D^{2} \leq 0$ (e.g. Hooper et al., 2005).

${ }^{4}$ This assumption on positive and increasing marginal costs of diversity provision is even more pronounced in our analysis because we use diversity indexes (e.g. the Shannon index) as measure for diversity. in the increases of such index due to farmers management actions (e.g. introducing an additional species) have saturating effects on such an index.

${ }^{5}$ In addition, certainty equivalents of these revenues will be presented.
} 
1979). Based on the conceptual framework introduced above, the expected mean yield level can be estimated in the econometric implementation as follows:

$$
y=f_{1}(D)+e_{1}
$$

In line with the grassland ecology literature (e.g. Hooper et al., 2005), $f_{1}($.$) is expected to be a concave$ function with $\mathrm{D}$, with $\partial f_{1} / \partial D \geq 0$ and $\partial^{2} f_{1} / \partial D^{2} \leq 0$. The square of the observed deviations from the expected yields, i.e. the residuals of equation 6 , represents the yield variance and thus can be used to estimate the relationship with species diversity:

$$
\sigma_{y}^{2}=\left[y-f_{1}(D)\right]^{2}=\left(e_{1}\right)^{2}=f_{2}(D)+e_{2}
$$

where $f_{2}($.$) represents the yield variance function that is expected to satisfy \partial f_{2} / \partial D \leq 0$ and $\partial^{2} f_{2} / \partial D^{2} \geq 0$, i.e. a convex function with $D$. Based on the assumptions made, these regression models exhibit heteroscadasticity, i.e. the variance of the error term $\left(e_{i}\right)$ is changing with the level of species diversity. This needs to be accounted for in the estimation process. Here, we use weighted regression approaches, with weights being equal to the inverse of the variance at a specific point. The applicability of this approach can be limited because the estimated variance of $e_{2}$ may not be necessarily positive. In cases where the estimated variance is indeed negative, Di Falco and Chavas (2006) suggest to use White heteroscedasticity corrected standard errors. This, however, would lead to different estimation methods used in the different equations and differences in estimation results may occur simply due to the different approaches used. To avoid this potential inconsistency, we use log-squared residuals to estimate a relationship between the variance and the explanatory variables. A re-transformation using exponentiation ensures consistent variance estimates used in the weighted regression scheme. To account for location and time effects, we add dummy variables in all estimation steps ${ }^{6}$.

We consider two easy to calculate indices representing species diversity $D$, namely the Shannon and the Simpson indices. Both indices are frequently used in ecological applications (e.g. Krebs, 1999, Hooper et al., 2005 for overviews), but weigh species abundances or biomass production slightly differently. The Shannon index is defined as $H^{\prime}=-\sum_{i=1}^{K} x_{i} \ln \left(x_{i}\right)$, with $x_{i}$ being the share of the biomass of species $^{7} \mathrm{i}(\mathrm{i}=1, \ldots \mathrm{K})$ that is present in the investigated grassland. The Simpson index is defined as $\lambda=$ $\sum_{i=1}^{K} x_{i}^{2}$. Both indices approach zero if the relative abundance of one species approaches unity (as in a monoculture). While the Shannon index is known to give greater weight to rare species by correcting species richness for differences in evenness, the Simpson index gives greater weight to abundant species (Roscher et al., 2013 and references therein). Nevertheless, both indices have been found to be useful in the Jena Experiment, as for many other studies before. For example, Roscher et al. (2013) studied the effect of species diversity on the spontaneous colonization over several years and found the temporal variability of the (relatively simple) Shannon index to be very similar to that of a (much more complex)

\footnotetext{
${ }^{6}$ Location is captured using a block dummy, which distinguishes four main homogeneous areas (i.e., blocks with respect to soil and water conditions) in the experimental set-up (see section 4 and Weigelt et al., 2010, for details).

${ }^{7}$ We focus on diversity at species level because this tends to be the standard unit of conservation and measurement (e.g. in the experimental data used here). But we are aware that also within-species genetic diversity can play an important role (e.g. Di Falco and Chavas, 2008).
} 
functional trait index. Here, we use both indices in our ecological economic assessment. This implies that we focus on realized instead of on sown diversity. Even though these measures are usually expected to show similar patterns, realized diversity may be influenced by a wider range of factors, comprising, for instance, local management and availability of resources (e.g. Fridley, 2002, Vogel et al., 2012), and thus may be the better indicator for (controllable) species diversity levels in the respective field or experimental site. In the Jena Experiment, which is base for our empirical analysis, sown and realized plant species richness/diversity are closely related (Marquard et al., 2009).

The econometric specification of equations 6 and 7 includes the choice of appropriate functional forms. To allow for sufficient flexibility and based on assumptions on the shape of these functions (e.g. Koellner and Schmitz, 2006, Marquard et al, 2009), we consider three options with the diversity index entering the regression either in linear or square root form as well as in a combination of both. Different model selection criteria (AIC, BIC, adjusted coefficient of determination) indicate that the square root specifications are superior for both equations.

In a second estimation approach, we additionally control for the presence of legumes in the experimental plots using a dummy variable in all estimation steps since legumes are expected to increase productivity (see section 2). Accounting also for this variable, we aim to identify whether effects of species diversity on mean and variance of grassland production solely originate from the presence of legumes or from a more general species diversity effect.

\subsection{Implementation and analysis}

In a next step, we combine the results from the ecological economic framework developed above with the econometric analysis. More specifically, the empirical relationships estimated according to equations 6 and 7 are used to derive absolute and marginal relationships between species diversity and benefits as well risk premia at different levels of species diversity. In this respect, assumptions on risk preferences of the farmer have to be made. To ensure flexibility in terms of the representation of these risk preferences in our analysis, we assume a power utility function $U=(1-\tau)^{-1} \pi^{1-\tau}$, so that $r=\tau / \pi$. Thus, this choice implies that the decision maker exhibits decreasing absolute risk aversion. Initially, we assume a specification of the utility function with $\tau=2$, reflecting a moderate level of risk aversion (Chavas, 2004). Furthermore, we assume a price of yield equal to $150 € / \mathrm{t}$ (of drymatter yield) (taken from http://www.proplanta.de). This analysis will result in point estimates of the absolute and marginal benefits and risk premia arising from different levels of species diversity.

However, the interpretation of such results as point estimates may be misleading because it does not reflect uncertainties and assumptions underlying our analysis. To overcome this problem, we conduct sensitivity analyses with respect to three aspects ${ }^{8}$ : First, we aim to reflect the uncertainties underlying

\footnotetext{
${ }^{8}$ In addition, we conducted a similar analysis using the Simpson index and come to qualitatively similar results as presented here for the Shannon index.
} 
our econometric analysis. Thus, a bootstrap approach is chosen where we repeat the estimation process for 999 bootstrap samples that have been randomly selected with replacement. The resulting 999 different estimates for mean and variance yield functions are used to estimate risk premia (at $\tau=2$ and $\mathrm{p}=150 € / \mathrm{t}$ ) and the resulting values for the benefits, risk premia, marginal benefits and insurance values are used to derive $95 \%$ confidence intervals. Second, we investigate uncertainties with respect to the assumptions made for the economic parameters, i.e. price levels and levels of risk aversion. Here, we repeat our analysis for a total of fifty specifications of the utility function, with $\tau$ ranging from 0 to 5 (at $\mathrm{p}=150 € / \mathrm{t}$ ). This range reflects the variation from risk neutral to very risk-averse behavior that has been revealed by German farmers (e.g. Maart-Noelck and Musshoff, 2014). Third, we repeat our analysis (at $\tau=2$ ) using price levels ranging from 100 to $200 € / \mathrm{t}$, representing the range of price fluctuations over recent years. The results of the latter two sensitivity analyses are presented using contour plots for revenue certainty equivalents and insurance values.

\section{$4 \quad$ Data}

We use biomass data obtained from the Jena Experiment, a large scale biodiversity experiment conducted in Germany (50 $55^{\prime} \mathrm{N}, 11^{\circ} 35 \mathrm{E}, 130 \mathrm{~m}$ altitude, see e.g. Roscher et al., 2004, and Weigelt et al., 2010 for details). For the period 1961-1990, the mean average temperature has been $9.3^{\circ} \mathrm{C}$, and the average annual precipitation in this period was $587 \mathrm{~mm}$. The experiment uses 82 main plots (which cover $20 \mathrm{~m}$ x $20 \mathrm{~m}$ each), in which different combinations of species are used, belonging to four plant functional groups (grasses, legumes, tall herbs, small herbs). More specifically, the species pool comprised 16 grasses, 12 legumes, 20 tall and 16 small herbs (see Roscher et al., 2004, for details). The species selection reflects the typical Central European flora found in semi-natural, species rich, hay meadows, traditionally used in the region (Roscher et al., 2004). All monocultures and mixtures, ranging from 2 -species to 60 -species mixtures, have been used in our assessment. To account for differences in soil and water conditions, the experimental site (in total about 10ha) was divided in 4 blocks and the 82 plots distributed equally across these blocks. We focus our analysis on data obtained from these 82 main plots, where 3-4 randomly selected sub-plots (each $0.2 \times 0.3 \mathrm{~m}$ ) were used for biomass harvests twice a year (typically late May and late August). Management conditions are constant across time and space and comprise biannual weeding and mowing (early June and early September), but no fertilization. The dataset used comprises 1455 observations and is taken from Weigelt et al. (2010); we employ observations for the period 2003-2008 ${ }^{9}$. Total target species biomass (dry matter yield) is used in our analysis. The mean biomass is $5.21 \mathrm{t} / \mathrm{ha}(\mathrm{SD}=3.81 \mathrm{t} / \mathrm{ha})$. The average Shannon and Simpson indices across sub-plots are $0.91(\mathrm{SD}=0.56)$ and $0.47(\mathrm{SD}=0.24)$, respectively.

\footnotetext{
${ }^{9}$ Data for 2002, the establishment year of the Jena Experiment, was not used because only one harvest took place and was thus not comparable with the management in the following years.
} 
Table 1 summarizes the estimation results following equations 6 and 7. In this first estimation approach, diversity effects are not controlled for the specific effect of legumes, but the focus is laid on species diversity effects in general. For both indices, we find evidence for the expected properties of species diversity to increase the mean and decrease the variance of grassland yields ${ }^{10}$. F-tests allow us to reject null hypotheses that the explanatory variables do not explain variation in the dependent variables.

Table 1. Estimation results of grassland produczion.

\begin{tabular}{lcc}
\hline \multicolumn{2}{c}{ Shannon Index } & Species Diversity (D) \\
\multicolumn{2}{c}{ a) Expected yields (Equation 6) } & Simpson Index \\
Intercept & $6.1866(16.43)^{* * *}$ & \\
$\mathrm{D}^{0.5}$ & $1.6099(5.59)^{* * *}$ & $6.7791(17.07)^{* * *}$ \\
$R_{a d j}^{2}$ (and F-Test) & $0.16^{\mathrm{xxx}}$ & $1.3719(3.14)^{* * *}$ \\
$\quad$ b) Variance of yields (Equation 7) & $0.15^{\mathrm{xxx}}$ \\
Intercept & $15.4379(4.91)^{* * *}$ & \\
$\mathrm{D}^{0.5}$ & $-3.9829(-1.76)^{*}$ & $18.1902(5.27)^{* * *}$ \\
$R_{a d j}^{2}$ (and F-Test) & $0.02^{\mathrm{xxx}}$ & $-9.52(-2.64)^{* * *}$ \\
\hline
\end{tabular}

Numbers in parentheses are t-values. * and *** denote significance levels at the $10 \%$ and $1 \%$ level, respectively. ${ }^{\mathrm{xxx}}$ denotes that the null hypothesis, i.e., the explanatory variables do not explain variation in dependent variables could be rejected by the F-test at the $1 \%$ level. $\mathrm{D}^{0.5}$ indicates the square root of the diversity index used (either Shannon or Simpson index). $R_{a d j}^{2}$ is the adjusted coefficient of determination. Note that plot location and year of the experiment have been accounted for using dummy variables (coefficients not shown), $d f=1436$.

In Table 2, estimation results are presented for which we took also the presence of legumes in the plots into account in both estimation steps. As expected, the presence of legumes has a significant positive effect on the mean yield levels. Even though the remaining effect of species diversity on mean yield levels is still positive, it is smaller compared to the estimation without accounting for legume presence (Table 1a). For the Simpson index, the effect is no longer significant (Table 2a). On the other hand, the results for the yield variance (Table 2b) show that the positive effect of legumes on mean yield levels also implies a significantly higher yield variance. In contrast, species diversity in general (expressed as Shannon or Simpson index) still has a significant negative effect on yield variance. It shows that this effect is even more distinct if controlling for the effects of the presence of legumes (comparing Tables 1 and 2).

\footnotetext{
${ }^{10}$ As indicated above, other model specifications (e.g. linear) have been rejected in favour of the square root specifications.
} 
Table 2. Estimation results - controlling for the effects of legumes.

Species Diversity (D)

Shannon Index

Simpson Index

a) Expected yields (Equation 6)

$\begin{array}{lll}\text { Intercept } & 5.34(15.07)^{* * *} & 5.83(15.24)^{* * *} \\ \mathrm{D}^{0.5} & 0.92(3.42)^{* * *} & 0.44(1.03) \\ \text { Legumes } & 2.81(16.04)^{* * *} & 2.91(16.76)^{* * *} \\ & 0.29^{\mathrm{xxx}} & 0.29^{\mathrm{xxx}} \\ R_{\text {adj }}^{2} \text { (and F-Test) } & \\ \quad \text { b) Variance of yields (Equation } 7) & 14.85(5.39)^{* * * *} \\ \text { Intercept } & 12.81(4.74)^{* * *} & -14.78(-4.88)^{* * *} \\ \mathrm{D}^{0.5} & -8.29(-4.06)^{* * *} & 10.36(8.15)^{* * *} \\ \text { Legumes }^{2} \text { (and F-Test) } & 10.53(7.82)^{* * *} & 0.06^{\mathrm{xxx}}\end{array}$

Numbers in parentheses are t-values. * and *** denote significance levels at the $10 \%$ and $1 \%$ level, respectively. ${ }^{\mathrm{xxx}}$ denotes that the null hypothesis, i.e., the explanatory variables do not explain variation in dependent variables, could be rejected by the F-test at the $1 \%$ level. $\mathrm{D}^{0.5}$ indicates the square root of the diversity index used (either Shannon or Simpson index). Legumes is a dummy indicating the presence of legumes. $R_{\text {adj }}^{2}$ is the adjusted coefficient of determination. Note that plot location and year of the experiment have been accounted for using dummy variables (coefficients not shown), $\mathrm{df}=1435$.

In summary, we find that species diversity increases expected levels of grassland production yields and decreases their variance, i.e. reduces production risks. The effect on expected yield levels is caused to a large extent by the presence of legumes in the (more diverse) species mixtures. In contrast, the risk reducing property of species diversity is even more distinct if controlling for the presence of legumes. However, since we aim quantifying the effects of species diversity in general and not only the functional group of legumes plays a special role in the Jena Experiment (Roscher et al., 2004, Marquard et al., 2009), we will proceed with the results displayed in Table 1. Furthermore, as the results presented above are similar for both diversity indicators, and to ensure clarity of presentation, we thus proceed in using one index only, i.e., the Shannon index.

Figure 1 shows certainty equivalent (of revenues) and risk premium (evaluated at $\tau=2$ and $p=150 € / t$ ) in relation to the Shannon index for realized species diversity in the grassland as well as the $95 \%$ confidence intervals around the estimates (dotted lines), which have been derived using non-parametric bootstrap. The confidence intervals represent the uncertainties underlying the results, arising from estimation errors for production yields and yield variance functions. Certainty equivalents of revenues are increasing with species diversity. As shown in Table 1, a higher Shannon index implies both higher and more stable yield levels, with both effects leading to increasing utility for a risk-averse decision maker. The latter property is furthermore illustrated by the fact that the risk premium is decreasing with 
increasing species diversity. The confidence intervals indicate that the findings presented in Table 1, i.e. that species diversity increases yield and decreases yield variance, are robust with respect to the sample composition.

Figure 1. Certainty equivalents and risk premium in relation to realized species diversity expressed with the Shannon index.

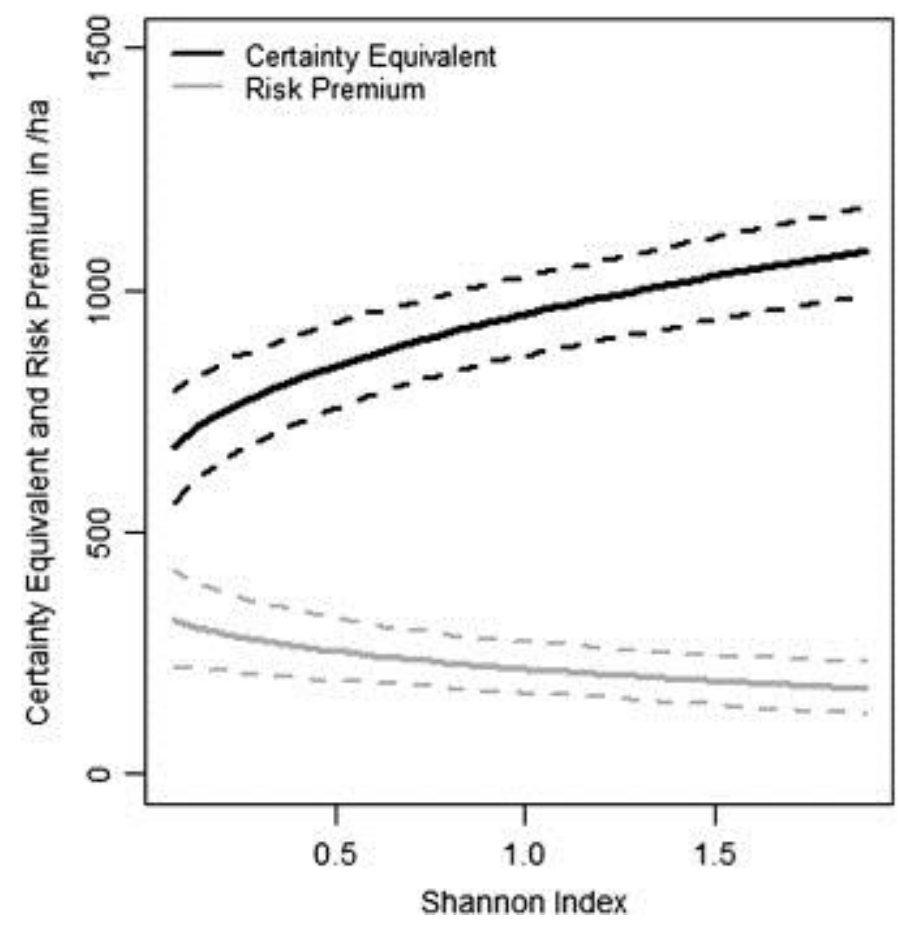

Dotted lines represent 95\% confidence intervals derived from non-parametric bootstrap.

The marginal benefits and insurance values of species diversity are shown in Figure 2. Again, 95\% confidence intervals derived from non-parametric bootstrap are presented (dotted lines). Due to the concavity of the production function and the convexity of the yield variance function, both values are decreasing with increasing values of the Shannon index. If the Shannon index approaches zero, i.e. in cases when the relative abundance of a single species approaches unity, as in a monoculture, marginal benefits and insurance values are highest. For instance, increasing the species diversity expressed by the Shannon index $H^{\prime}$ at a point where it is close to zero by one unit would imply a risk reducing effect (insurance value) being equivalent to more than $200 € /$ ha. Note, however, that an increase of the Shannon index by one unit reflects a substantial change in species diversity; for comparison, the interquartile range of the Shannon index in our sample is $0.53-1.29$. The confidence intervals indicate that inference on the marginal effects of species diversity is subject to high levels of uncertainty as introduced by the estimations steps. In particular, it shows that inference drawn for low levels of species diversity is associated with a higher level of uncertainty than for high levels of diversity. However, the levels of marginal benefits and insurance values resulting from the resampling procedure are consistently 
positive, underlining the conclusion that species diversity is clearly associated with both positive marginal benefits and positive insurance values.

Figure 2. Marginal benefits and insurance values of species diversity.

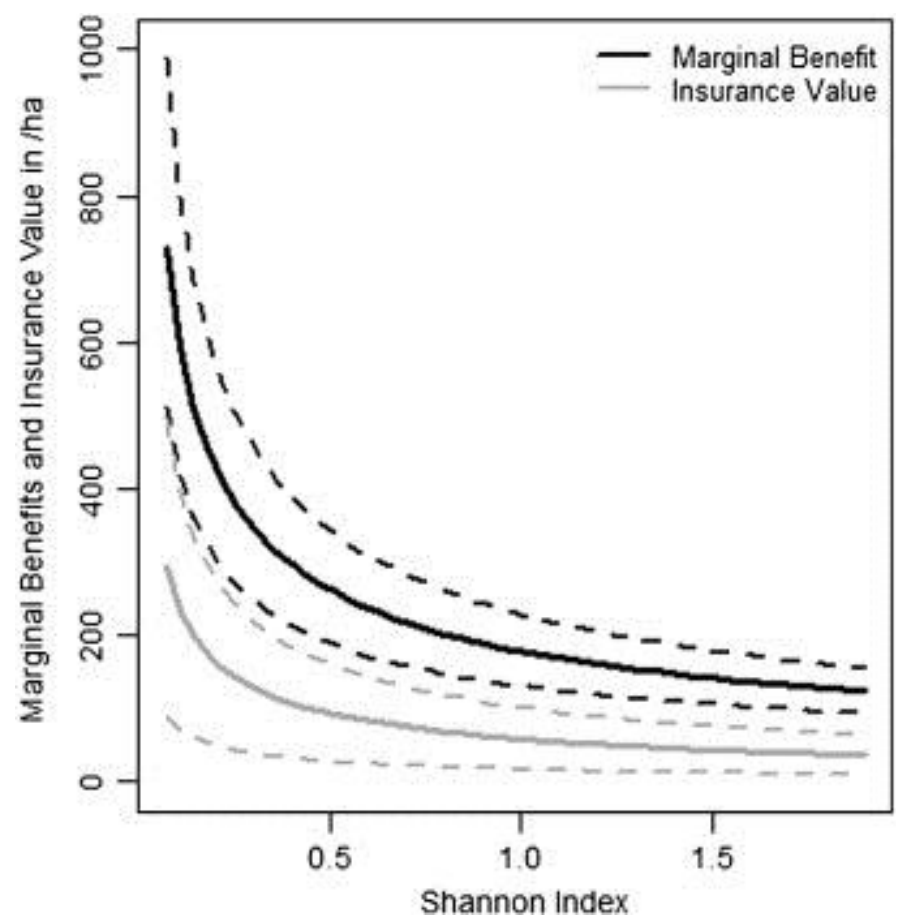

Dotted lines represent 95\% confidence intervals derived from non-parametric bootstrap.

Next, we present results of the sensitivity analysis with respect to the level of output prices, summarized using contour plots. Figure 3 shows the levels of certainty equivalents (Of revenues) in relation to both the output price and the species diversity level. Lines represent iso-certainty equivalent curves, indicating all combinations of price levels and species diversity that lead to the identical level of certainty equivalent for the farmer. Certainty equivalents increase with both output prices and species diversity. For instance, at a price of $150 € / \mathrm{t}$, increasing $H^{\prime}$ from 0.5 to 1.5 increases the certainty equivalents from about 800 to about $975 € /$ ha (Fig. 3). The iso-certainty equivalent curves are convex to the origin, indicating that output price and species diversity are substitutes in terms of farmers' utility, while the marginal rate of substitution (the slope of iso-certainty equivalent curves) is decreasing. The results displayed in Figure 3 underline that benefits from grassland production can vary substantially in the range of observed prices and species diversity. 
Figure 3. Results from sensitivity analysis: contour lines of certainty equivalents (in $€ /$ ha) for different combinations of species diversity and prices.

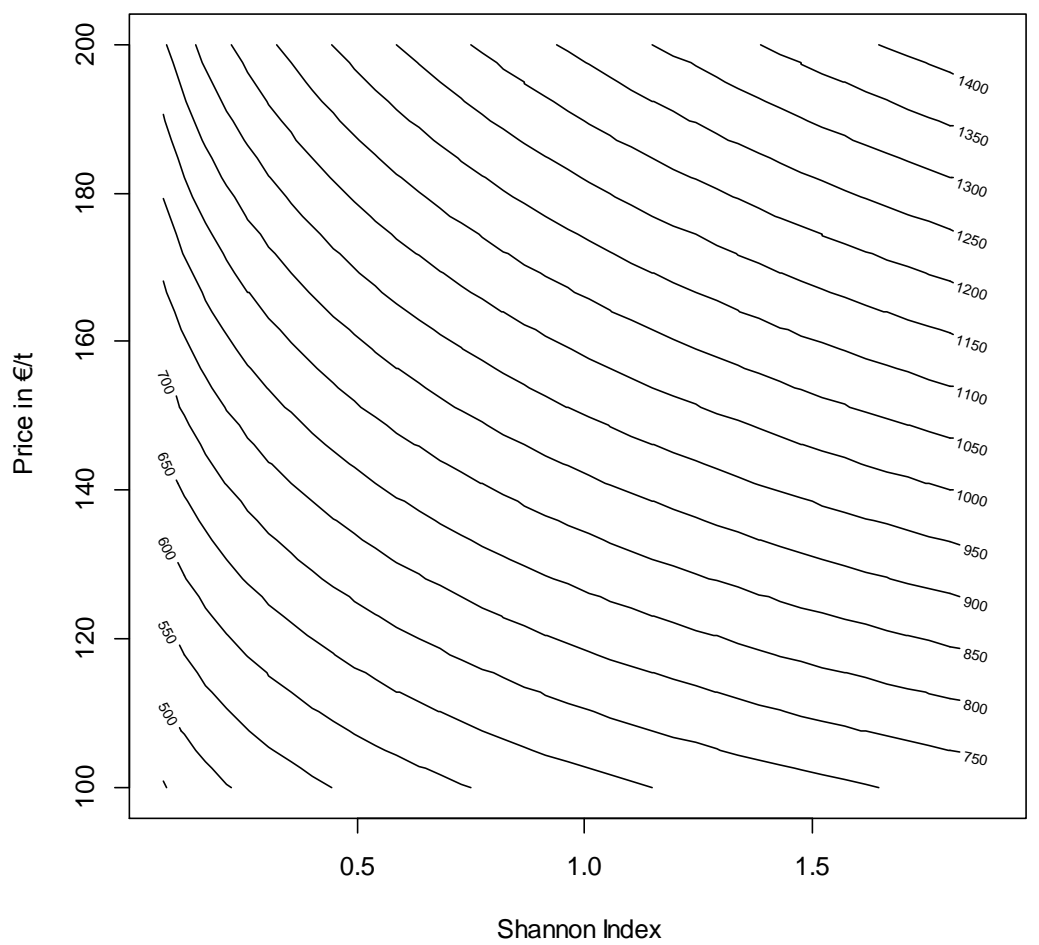

Figure 4 shows the contour plots for the insurance value of species diversity derived from the sensitivity analysis with respect to output price levels. Supporting the theoretical findings presented in section 3, it illustrates that the insurance value of species diversity is increasing with the output price and decreasing with species diversity. But even for conditions with high species diversity and low output prices (i.e., the bottom right corner of Figure 4), these insurance values are clearly above zero, i.e. even at these points, there is a significant insurance value of species diversity. However, to what extent farmers would be willing to invest in species diversity in those situations depends on the costs of its provision. 
Figure 4. Results from sensitivity analysis: contour lines of insurance values of species diversity (in $€ /$ ha) for different combinations of species diversity and prices.

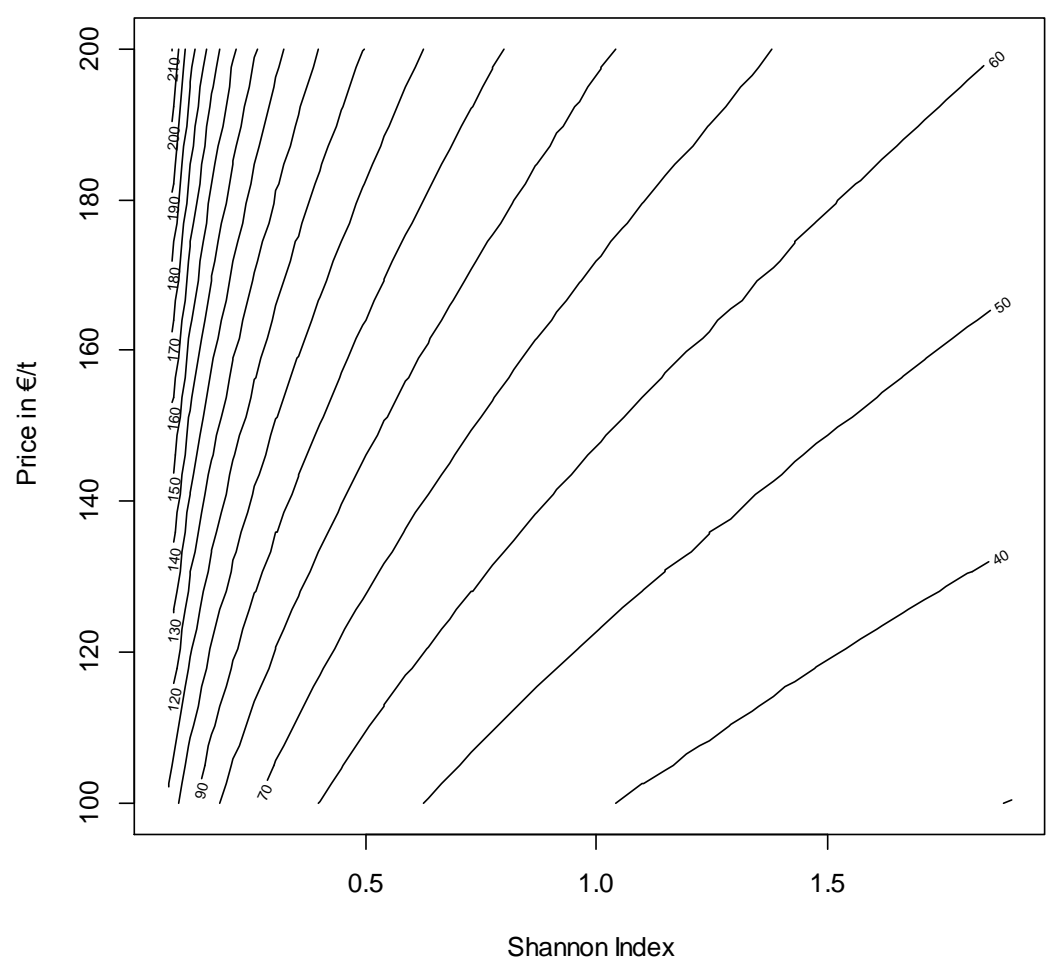

Next, we conduct a sensitivity analysis with respect to the level of risk aversion. Figure 5 shows that certainty equivalents are (again) increasing in species diversity, but decrease with increasing risk aversion. For instance, for a situation when $H^{\prime}$ equals to one, a shift from risk neutrality $(\tau=0)$ to very high risk aversion $(\tau=5)$ leads to a reduction of certainty equivalents from about 1150 to about $800 € /$ ha, representing the increase of the risk premium. The shape of the iso-certainty equivalent curves also indicates that gains in certainty equivalents due to increasing species diversity are higher for more risk-averse decision makers. 
Figure 5. Results from sensitivity analysis: contour lines of certainty equivalents (in $€ /$ ha) for different combinations of species diversity and coefficients of risk aversion.

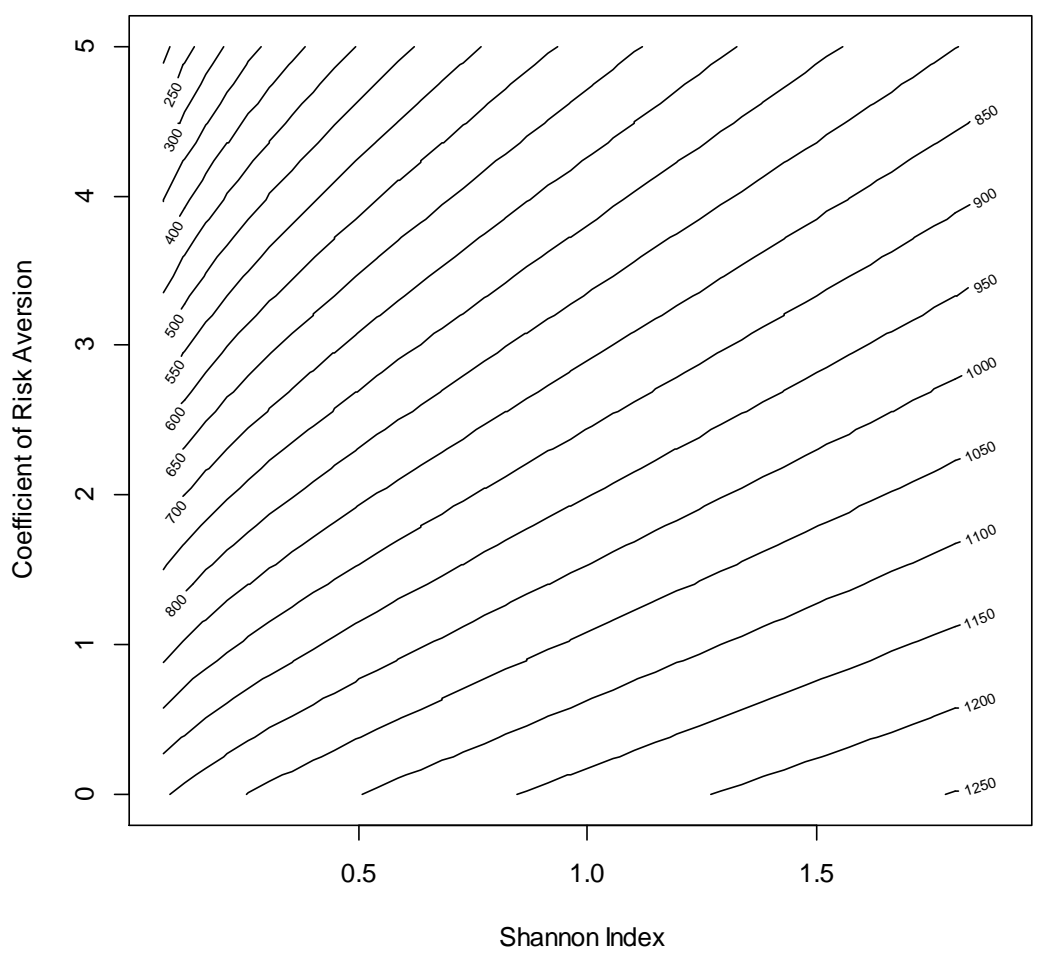

This property is also illustrated by the fact that the insurance value of species diversity is higher for more risk-averse decision makers, while the insurance value of species diversity is equal to zero if the farmer is risk neutral, as shown in Figure 6. Furthermore, for a fixed level of risk aversion, the insurance value is decreasing with the Shannon index. Figure 6 also illustrates the earlier stated finding (e.g. section 3) that the insurance value increases with the level of risk aversion. 
Figure 6. Results from sensitivity analysis: contour lines of insurance values of species diversity (in $€ /$ ha) for different combinations of species diversity and coefficients of risk aversion.

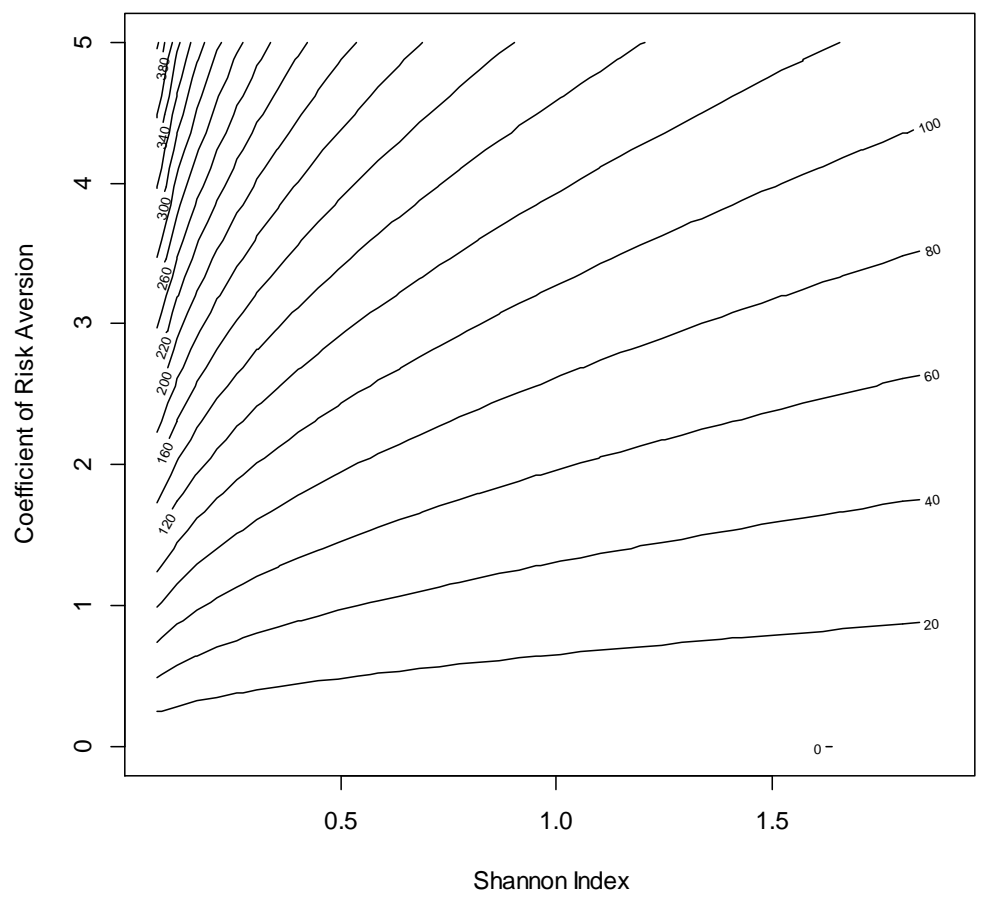

\section{Discussion and Conclusion}

As often reported in the ecological literature, species diversity in grasslands increases expected production levels and decreases the variability of grassland yields, with the Jena Experiment, the empirical base for our analysis, being no exception. Note that our assessment of risk-reducing effects of species diversity is thus based on a data set with an extensive management regime (biannual mowing and no fertilization), which may limit the transferability of results. However, the overall biodiversityproductivity relationship is in line with many other studies (e.g. Cardinale et al. 2012, Hector et al., 1999, Hooper et al., 2012, Isbell et al., 2011, Tilman et al., 2005), including North American prairies (e.g. Tilman et al., 2006) and intensively managed grasslands across Europe (e.g. Kirwan et al., 2007), and thus applies to many different species compositions, environmental settings and management intensities. Increasing yields with increasing species diversity are typically explained by the niche complementarity concept (see section 2 for details). In addition, not only grassland yields and their stability increase with increasing biodiversity, but also many other beneficial ecosystem functions which provide relevant ecosystem services in agriculture, such as pollination, efficient soil nitrogen use (and thus less nitrate leaching), and insurance against weed pressure (e.g. Balvanera et al., 2006, Allan et al., 2013), adding to a basic (but critical) conservation aspect when maintaining grassland species diversity 
(Hoekstra et al., 2005). Overall, we conclude that biodiversity might be considered an additional production factor in grassland management.

In our analysis, we expand this ecological perspective, develop an ecological economic and an econometric framework, and quantify the (monetary) value of this stabilizing and thus risk reducing effect from the perspective of a risk-averse farmer. We find species diversity to have a significant monetary insurance value for risk-averse decision makers, a result which is robust to the boundary conditions considered in various sensitivity analyses. In practice, farmers can influence species diversity with a wide range of management practices, such as sown diversity as well as adjustments of fertilization and mowing practices. Not accounting for the here revealed yield stabilizing property would lead to an underestimation of the values of on-field species diversity from a farmer's perspectives. Taking into account that the risk reduction property of plant diversity is perceived as an important risk reducing factor by farmers and farm advisors (e.g. Lugnot and Martin, 2013), this finding has important implications both at the farm and at the aggregated level ${ }^{11}$. For instance, our results underline that farmers' reliance on diversity can be an essential part of their ex-ante risk management strategies (e.g. Di Falco and Chavas, 2009). Moreover, our results suggst that farmers' risk preferences may shape agroecosystem diversity (e.g. Di Falco, 2012, Mouysset et al., 2013). This is particularly important because on-farm diversity has positive external effects (see above and e.g. Baumgärtner and Quaas, 2010, Marggraf, 2003). These external effects have not been considered in our analysis, but may introduce a potential rationale for governmental support of management practices leading to speciesrich grasslands. In future research, the investigation presented here should be extended in the following directions: i) The yield perspective should be extended by also considering energy values of grassland yields (e.g. for fodder or bio-energy use) or grassland nitrogen use, not solely focusing on physical yield levels. ii) Further evidence is needed if and how farmers perceive the relationships revealed here in agricultural practice and how this influences management decisions. iii) Decisions under uncertainty regarding on-farm species diversity should be considered at larger scales, e.g., at farm- or regional levels.

\footnotetext{
${ }^{11}$ See Lüscher et al., (2014) for a recent discussion on appropriate metrics for communication of diversity to farmers.
} 


\section{References}

Allan, E., Weisser, W.W., Fischer, M., Schulze, E.D., Weigelt, A., Roscher, C., Baade, J., Barnard, R., Beßler, H., Buchmann, N., Ebeling, A., Eisenhauer, N., Engels, C., Fergus, A., Gleixner, G., Gubsch, M., Halle, S., Klein, A.M., Kertscher, I., Kuul, A., Lange, M., LeRoux, X., Meyer, S., Migunova, V.D., Milcu, A., Niklaus, P., Oelmann, Y., Pašalić, E., Petermann, J., Poly, F., Rottstock, T., Sabais, A., Scherber, C., Scherer-Lorenzen, M., Scheu, S., Steinbeiss, S., Schwichtenberg, G., Temperton, V., Tscharntke, T., Voigt, W., Wilcke, W., Wirth, C., Schmid, B. (2013). A comparison of the strength of biodiversity effects across multiple functions. Oecologia 173: 223-237

Balvanera, P., Pfisterer, A.B., Buchmann, N., He, J.S., Nakashizuka, T., Raffaelli, D., and Schmid, B. (2006). Biodiversity and ecosystem functioning: a meta-analysis of experimental results. Ecology Letters 9: 1146-1156.

Baumgärtner, S. (2007). The insurance value of biodiversity in the provision of ecosystem services. Natural Resource Modeling, 20(1): 87-127.

Baumgärtner, S., and Quaas, M. F. (2009). Ecological-economic viability as a criterion of strong sustainability under uncertainty. Ecological Economics 68(7): 2008-2020.

Baumgärtner, S., and Quaas, M. F. (2010). Managing increasing environmental risks through agrobiodiversity and agrienvironmental policies. Agricultural Economics 41(5): 483-496.

Bessler, H., Oelmann, Y., Roscher, C., Buchmann, N., Scherer-Lorenzen, M., Schulze, E.D., Temperton, V.M., Wilcke, W. and Engels, C. (2012). Nitrogen uptake by grassland communities: contribution of N2 fixation, facilitation, complementarity, and species dominance. Plant and Soil 358:301-322

Caldeira, MC, Ryel RJ, Lawton JH, Pereira JS (2001) Mechanisms of positive biodiversity-production relationships: insights provided by $\delta^{13} \mathrm{C}$ analysis in experimental Mediterranean grassland plots. Ecology Letters 4: 439-443.

Cardinale, B. J., J. E. Duffy, A. Gonzalez, D. U. Hooper, C. Perrings, P. Venail, A. Narwani, G. M. Mace, D. Tilman, D. A. Wardle, A. P. Kinzig, G. C. Daily, M. Loreau, J. B. Grace, A. Larigauderie, D. S. Srivastava, and S. Naeem. 2012. Biodiversity loss and its impact on humanity. Nature 486:5967

Chavas, J. P. (2004). Risk analysis in theory and practice. Elsevier.

De Boeck H.J., C.M.H.M. Lemmens, H. Bossuyt, S. Malchair, M. Carnol, R. Merckx, and R. Ceulemans. 2006. How do climate warming and plant species richness affect water use in experimental grasslands? Plant and Soil 288: 249-261.

Derissen, S., Quaas, M. F., and Baumgärtner, S. (2011). The relationship between resilience and sustainability of ecological-economic systems. Ecological Economics 70(6): 1121-1128.

Di Falco, S. (2012). On the value of agricultural biodiversity. Annual Review of Resource Economics 4(1): 207-223. 
Di Falco, S., and Chavas, J. P. (2006). Crop genetic diversity, farm productivity and the management of environmental risk in rainfed agriculture. European Review of Agricultural Economics 33(3): 289314.

Di Falco, S., and Chavas, J. P. (2008). Rainfall shocks, resilience, and the effects of crop biodiversity on agroecosystem productivity. Land Economics 84(1): 83-96.

Di Falco, S., and Chavas, J. P. (2009). On crop biodiversity, risk exposure, and food security in the highlands of Ethiopia. American Journal of Agricultural Economics 91(3): 599-611.

Di Falco, S., and Perrings, C. (2005). Crop biodiversity, risk management and the implications of agricultural assistance. Ecological Economics 55(4): 459-466.

Dörschner, T. and Musshoff, O. (2013). Cost-oriented evaluation of ecosystem services under consideration of income risks and risk attitudes of farmers. Journal of Environmental Management 127: 249-254.

Ehrlich, P.R., and A.H. Ehrlich. (1981). Extinction: the Causes and Consequences of the Disappearance of Species. Random House, New York, NY

Fargione J., D. Tilman, R. Dybzinski, J. Hille Ris Lambers, C. Clark, S.W. Harpole, J.M.H. Knops, P.B. Reich, and M. Loreau. (2007). From selection to complementarity: shifts in the causes of biodiversity-productivity relationships in a long-term biodiversity experiment. Proceedings of the Royal Society B 274: 871-876.

Fridley, J. D. (2002). Resource availability dominates and alters the relationship between species diversity and ecosystem productivity in experimental plant communities. Oecologia 132(2): 271277.

Gubsch M., N. Buchmann, B. Schmid, E.D. Schulze, A. Lipowsky, and C. Roscher. 2011. Differential effects of plant diversity on functional trait variation of grass species. Annals of Botany 107: 157169.

Haddad, N. M., Crutsinger, G. M., Gross, K., Haarstad, J., Tilman, D. (2011). Plant diversity and the stability of foodwebs. Ecology Letters 14(1): 42-46.

Hautier, Y., Niklaus, P.A., and Hector, A. (2009) Competition for light causes plant biodiversity loss after eutrophication. Science 324: 636.

Hector, A., Schmid, B., Beierkuhnlein, C., Caldeira, M. C., Diemer, M., Dimitrakopoulos, P. G., JA Finn, H Freitas, PS Giller, J Good, R Harris, P Högberg, K Huss-Danell, J Joshi, A Jumpponen, Ch Körner, PW Leadley, M Loreau, A Minns, CPH Mulder, G O'donovan, SJ Otway, JS Pereira, A Prinz, DJ Read, M Scherer-Lorenzen, E-D Schulze, A-SD Siamantziouras, EM Spehn, AC Terry, AY Troumbis, FI Woodward, S Yachi, Lawton, J. H. (1999). Plant diversity and productivity experiments in European grasslands. Science, 286(5442): 1123-1127.

Hector, A., Hautier, Y., Saner, P., Wacker, L., Bagchi, R., Joshi, J., M. Scherrer-Lorenzen, E. M. Spehn, E. Bazeley-White, M. Weilenmann, M. C. Caldeira, P. G. Dimitrakopoulos, J. A. Finn, K. Huss- 
Danell, A. Jumpponen, C. P. H. Mulder, C. Palmborg, J. S. Pereira, A. S. D. Siamantziouras, A. C. Terry, A. Y. Troumbis, B. Schmid, Loreau, M. (2010). General stabilizing effects of plant diversity on grassland productivity through population asynchrony and overyielding. Ecology 91(8): 22132220.

Hodgson JG, Montserrat-Marti G, Tallowin J, Thompson K, Díaz S, Cabido M, Grime JP, Wilson PJ, Band SR, Bogard A, Cabido R, Caceres D, Castro-Diez P, Ferrer C, Maestro-Martinez M, PerezRontome MC, Charles M, Cornelissen JHC, Dabbert S, Perez-Harguindeguy N, Krimly T, Sijtsma FJ, Strijker D, Vendramini F, Guerrero-Campo J, Hynd A, Jones G, Romo-Diez A, Espuny LD, Villar-Salvador P, Zak MR (2005) How much will it cost to save grassland diversity? Biological Conservation 122:263-273

Hoekstra JM, Boucher TM, Ricketts TH, Roberts C. (2005). Confronting a biome crisis: Global disparities of habitat loss and protection. Ecology Letters 8: 23-29.

Hooper, D. U., Chapin Iii, F. S., Ewel, J. J., Hector, A., Inchausti, P., Lavorel, S., J. H. Lawton, D. M. Lodge, M. Loreau, S. Naeem, B. Schmid, H. Setälä, A. J. Symstad, J. Vandermeer, and Wardle, D. A. (2005). Effects of biodiversity on ecosystem functioning: a consensus of current knowledge. Ecological Monographs 75(1): 3-35.

Hooper, D. U., E. C. Adair, B. J. Cardinale, J. E. K. Byrnes, B. A. Hungate, K. L. Matulich, A. Gonzalez, J. E. Duffy, L. Gamfeldt, and O'Connor, M. I. (2012). A global synthesis reveals biodiversity loss as a major driver of ecosystem change. Nature 486:105-108.

Huston, M.A. (1997). Hidden treatments in ecological experiments: re-evaluating the ecosystem function of biodiversity. Oecologia 110: 449-460

Isbell, F., V. Calcagno, A. Hector, J. Connolly, W. S. Harpole, P. B. Reich, M. Scherer-Lorenzen, B. Schmid, D. Tilman, J. van Ruijven, A. Weigelt, B. J. Wilsey, E. S. Zavaleta, and Loreau, M. (2011). High plant diversity is needed to maintain ecosystem services. Nature 477:199-202.

Just, R. E., and Pope, R. D. (1978). Stochastic specification of production functions and economic implications. Journal of Econometrics 7(1): 67-86.

Just, R. E., and Pope, R. D. (1979). Production function estimation and related risk considerations. American Journal of Agricultural Economics 61(2): 276-284.

Kahmen, A., J. Perner, and N. Buchmann. (2005). Diversity-dependent productivity in semi-natural grasslands following climate perturbations. Functional Ecology 19: 594-601

Kirwan, L., M. T. Sebastià, J. A. Finn, R. P. Collins, C. Porqueddu, A. Helgadottir, O. H. Baadshaug, C. Brophy, C. Coran, S. Dalmannsdóttir, I. Delgado, A. Elgersma, M. Fothergill, B. E. FrankowLindberg, P. Golinski, P. Grieu, A. M. Gustavsson, M. Höglind, O. Huguenin-Elie, C. Iliadis, M. Jørgensen, Z. Kadziuliene, T. Karyotis, T. Lunnan, M. Malengier, S. Maltoni, V. Meyer, D. Nyfeler, P. Nykänen-Kurki, J. Parente, H. J. Smit, U. Thumm, and J. Connolly. (2007) Evenness 
drives consistent diversity effects in an intensive grassland system across 28 European sites. Journal of Ecology 95: 530-539.

Koellner, T., and Schmitz, O. J. (2006). Biodiversity, ecosystem function, and investment risk. BioScience 56(12): 977-985.

Krebs CJ (1999). Ecological methodology. Addison-Welsey, MenloPark

Lehman, C. L., and Tilman, D. (2000). Biodiversity, stability, and productivity in competitive communities. The American Naturalist 156(5): 534-552.

Lin, B. B. (2011). Resilience in agriculture through crop diversification: adaptive management for environmental change. BioScience 61(3): 183-193.

Loreau, M., S. Naeem, and P. Inchausti. (2002) Biodiversity and ecosystem functioning: a current synthesis. Oxford University Press.

Lugnot, M., and Martin, G. (2013). Biodiversity provides ecosystem services: scientific results versus stakeholders' knowledge. Regional Environmental Change 13(6): 1145-1155.

Lüscher G., Schneider M. K., Turnbull L. A, Arndorfer M., Bailey D., Herzog F., Pointereau P., Richner N., Jeanneret P. (2014). Appropriate metrics to inform farmers about species diversity. Environmental Science \& Policy. 41, 2014, 52-62

Maart-Noelck, S. C., and Musshoff, O. (2014). Measuring the risk attitude of decision-makers: are there differences between groups of methods and persons?. Australian Journal of Agricultural and Resource Economics 58(3): 336-352.

Marggraf, R. (2003). Comparative assessment of agri-environment programmes in federal states of Germany. Agriculture, ecosystems \& environment 98(1): 507-516.

Marquard, E., Weigelt, A., Temperton, V.M., Roscher, C., Schumacher, J., Buchmann, N., Fischer, M., Weisser, W.W., and Schmid, B. (2009) Plant species richness and functional composition drive overyielding in a 6-year grassland experiment. Ecology 90: 3290-3302.

McCann, K.S. (2000). The diversity-stability debate. Nature 405: 228-233.

Mouysset, L., Doyen, L., and Jiguet, F. (2013). How does economic risk aversion affect biodiversity?. Ecological Applications 23(1): 96-109.Mulder, C. P. H., Bazeley-White, E., Dimitrakopoulos, P. G., Hector, A., Scherer-Lorenzen, M., and Schmid, B. (2004). Species evenness and productivity in experimental plant communities. Oikos 107(1): 50-63.Naeem, S., and S. Li. (1997). Biodiversity enhances ecosystem reliability. Nature 390: 507-509.

Oelmann Y., N. Buchmann, G. Gleixner, M. Habekost, C. Roscher, S. Rosenkranz, E.D. Schulze, S. Steinbeiss, V.M. Temperton, A. Weigelt, W.W. Weisser, and W. Wilcke. (2011). Plant diversity effects on aboveground and belowground $\mathrm{N}$ pools in temperate grassland ecosystems: Development in the first five years after establishment. Global Biogeochemical Cycles 25, GB2014, doi:10.1029/2010GB003869 
Proulx, R., Wirth, C., Voigt, W., Weigelt, A., Roscher, C., Attinger, S., Baade, J., Barnard, R.L., Buchmann, N., Buscot, F., Eisenhauer, N., Fischer, M., Gleixner, G., Halle, S., Hildebrandt, A., Kowalski, E., Kuu, A., Lange, M., Milcu, A., Niklaus, P.A., Oelmann, Y., Rosenkranz, S., Sabais, A., Scherber, C., Scherer-Lorenzen, M., Scheu, S., Schulze, E.-D., Schumacher, J., Schwichtenberg, G., Soussana, J.-F., Temperton, V.M., Weisser, W.W., Wilcke, W., and Schmid, B., (2010). Diversity promotes temporal stability across levels of ecosystem organization in experimental grasslands. PLoS One 5(10): e13382.

Roscher, C., J. Schumacher, J. Baade, W. Wilcke, G. Gleixner, W. W. Weisser, B. Schmid, and E. D. Schulze. (2004). The role of biodiversity for element cycling and trophic interactions: an experimental approach in a grassland community. Basic and Applied Ecology 5:107-121.

Roscher, C., H. Beßler, Y. Oelmann, C. Engels, W. Wilcke, and E.-D. Schulze. (2008). Resources, recruitment limitation and invader species identity determine pattern of spontaneous invasion in experimental grasslands. Journal of Ecology 97: 32-37

Roscher C., B. Schmid, N. Buchmann, and Schulze, E.D. (2011a). Legume species differ in the responses of their functional traits to plant diversity. Oecologia 165:437-52.

Roscher C., M. Scherer-Lorenzen, J. Schumacher, V.M. Temperton, N. Buchmann, and Schulze, E.D.. (2011b). Plant resource-use characteristics as predictors for species contribution to community biomass in experimental grasslands. Perspectives in Plant Ecology, Evolution and Systematics 13: $1-13$.

Roscher C., S. Thein, A. Weigelt, V.M. Temperton, N. Buchmann, and Schulze, E.D. (2011c). $\mathrm{N}_{2}$ fixation and performance of 12 legume species in a 6-year grassland biodiversity experiment. Plant Soil 341:333-348

Roscher, C., Fergus, A. J., Petermann, J. S., Buchmann, N., Schmid, B., Schulze, E. D. (2013). What happens to the sown species if a biodiversity experiment is not weeded?. Basic and Applied Ecology 14(3): 187-198.

Sanderson, M. A., Skinner, R. H., Barker, D. J., Edwards, G. R., Tracy, B. F., and Wedin, D. A. (2004). Plant species diversity and management of temperate forage and grazing land ecosystems. Crop Science 44(4): 1132-1144.

Schläpfer, F., Tucker, M., and Seidl, I. (2002). Returns from hay cultivation in fertilized low diversity and non-fertilized high diversity grassland. Environmental and Resource Economics 21(1): 89-100.

Spehn E.M., J. Joshi, B. Schmid, M. Diemer, and Körner, C. (2000). Above-ground resource use increases with plant species richness in experimental grassland ecosystems. Functional Ecology 14: $326-337$.

Temperton, V.M., P. N. Mwangi, M. Scherer-Lorenzen, B. Schmid, and N. Buchmann. (2007). Positive interactions between nitrogen-fixing legumes and four different neighbouring species in a biodiversity experiment. Oecologia 151 (2): 190-205. 
Tilman, D., Polasky, S., and Lehman, C. (2005). Diversity, productivity and temporal stability in the economies of humans and nature. Journal of Environmental Economics and Management 49(3): 405426.

Tilman, D., Reich, P.B., Knops, J.H.M (2006). Biodiversity and ecosystem stability in a decade-long grassland experiment. Nature 441: 629-632.

van Ruijven, J. and Berendse, F.(2003). Positive effects of plant species diversity on productivity in the absence of legumes. Ecology Letters 6: 170-175

Vogel, A., Scherer-Lorenzen, M., and Weigelt, A. (2012). Grassland resistance and resilience after drought depends on management intensity and species richness. PloS one 7(5): e36992.

Walker, B., Kinzig, A., and Langridge, J. (1999). Original articles: plant attribute diversity, resilience, and ecosystem function: the nature and significance of dominant and minor species. Ecosystems 2(2): $95-113$.

Weigelt, A., Marquard, E., Temperton, V.M., Roscher, C., Scherber, C., Mwangi, P.N., von Felten, S., Buchmann, N., Schmid, B., Schulze, E.D., and Weisser W.W .(2010) The Jena-Experiment: six years of data from a grassland biodiversity experiment. Ecology 91: 930, Ecological Archives E091-066

Yachi, S., and Loreau, M (1999). Biodiversity and ecosystem productivity in a fluctuating environment: The insurance hypothesis. Proceedings of the National Academy of Science 96: 1463-1468. 